\title{
Obrigações em contratos de concessão para exploração e produção de petróleo e gás natural
}

\author{
Conselho Administrativo de Defesa Econômica (Cade)
}

Consulta no 08700.000207/2014-02

Consulente: Instituto Brasileiro de Petróleo, Gás e Biocombustíveis

Advogados: Leonardo Peres da Rocha e Silva, José Alexandre Buaiz Neto, Vicente Coelho Araújo, Daniel Costa Rebello, Marco Aurélio Martins Barbosa e outros

Relator: Conselheiro Eduardo Pontual Ribeiro

Voto-Vista: Conselheiro Gilvandro Vasconcelos Coelho de Araujo

\section{EMENTA}

Consulta. Obrigatoriedade de notificação de operações consistentes na cessão de direitos e obrigações referentes a contratos de concessão para exploração e produção de petróleo e gás natural. Mercado de exploração e produção de petróleo e gás natural. Conhecimento. Obrigatoriedade de notificação de cessões de direitos e obrigações que resultam na troca de posição contratual nos contratos de concessão de exploração e produção de petróleo.

\section{PALAVRAS-CHAVE}

Consulta; cessões de direitos e obrigações; contrato de concessão; exploração e produção de petróleo e gás natural. 


\section{Voto-vista}

\section{Relatório}

1. Em 10 de janeiro de 2014, o Instituto Brasileiro de Petróleo, Gás e Biocombustíveis ("IBP") apresentou a presente Consulta, requerendo que este Conselho se manifeste sobre a obrigatoriedade de notificação de operações de cessão de direitos e obrigações referentes a contratos de concessão para exploração e produção de petróleo e gás natural, os chamados contratos de concessão E\&P.

2. Consoante o IBP, a cessão de direitos e obrigações que implique a "mera alteração da titularidade do contrato de concessão" se enquadraria na hipótese de isenção de notificação prevista no artigo 90, parágrafo único, da Lei no 12.529/2011, por ser um "contrato decorrente" do contrato de concessão.

3. Além disso, de acordo com o IBP, as cessões de direitos e obrigações que resultem na troca de posição contratual nos contratos de concessão E\&P seriam neutras do ponto de vista concorrencial, vez que não implicariam transferência de participação de mercado ou aquisição de participações societárias e/ou de controle de empresa.

4. Na 45a Sessão Ordinária de Distribuição, a presente Consulta foi distribuída ao Conselheiro Eduardo Pontual Ribeiro, que solicitou que a Procuradoria Federal Especializada deste Conselho ("PFE/Cade") se manifestasse sobre o caso.

5. A PFE/Cade, então, emitiu o Parecer no 57/2014, observando estarem presentes os requisitos para o conhecimento da presente consulta, pelas seguintes razões:

a) A consulta em questão versa sobre comportamentos específicos que se encontram em andamento no segmento dos contratos voltados à exploração e produção de petróleo e gás natural. Com efeito, não se trata de questões abstratas ou genéricas formuladas em tese sobre alguma questão concorrencial, mas sim sobre operações que têm sido submetidas concretamente ao Cade à luz da Lei no $12.529 / 2011$;

b) A consulente promoveu o pagamento da taxa prevista em Lei (fls. 61 e fls. 83/84), além de ter promovido a instrução do pedido com os documentos que entende pertinentes para o deslinde da controvérsia; 
c) A consulta não tem como objeto a promoção de concorrência em órgãos do governo, tampouco veicula denúncia de infração contra a ordem econômica ou trata de dados técnicos, instrutórios ou mercadológicos que somente poderiam ser examinados no procedimento próprio de controle de estruturas de mercado;

d) A legitimidade do consulente afigura-se inconteste, dada a pertinência entre o seu objeto de atuação e o segmento de mercado de exploração e produção de petróleo e gás natural, circunstância hábil a configurar o interesse jurídico da requerente;

e) Não se está a tratar de fatos potencialmente atingidos pela prescrição administrativa.

6. No que tange ao mérito, a PFE/Cade entendeu pela perda superveniente do objeto da consulta, tendo em vista que a discussão em torno da necessidade ou não de notificação de operações de cessões de direitos e obrigações referentes aos contratos de concessão E\&P já foi enfrentada por este Conselho no julgamento recente de 3 Atos de Concentração, ${ }^{1}$ ocasiões nas quais o Tribunal foi unânime no sentido de que tais operações devem ser notificadas.

7. Assim, na 38 $8^{\underline{a}}$ Sessão Ordinária de Julgamento, o Conselheiro-Relator Eduardo Pontual Ribeiro exarou seu voto, acompanhando integralmente o entendimento da PFE, isto é, conhecendo a consulta, porém julgando-a prejudicada no mérito por considerar que "as questões trazidas pela Consulente já estão suficientemente respondidas nos votos e deliberações tomados por este Tribunal quando do julgamento dos Atos de Concentração que veicularam contratos de cessão de direitos de exploração e produção de petróleo".

8. Dessa forma, a fim de aprofundar o estudo acerca da questão em debate, solicitei vista do processo.

\section{Instituto da consulta}

\section{II.1 Breve histórico}

1. O instituto da consulta, no âmbito do Sistema Brasileiro de Defesa da Concorrência ("SBDC"), surgiu com a Lei no

1 Atos de Concentração n os 08700.005775/2013-19, 08700.008289/2013-52 e 08700.008292/2013-76. 
de as partes que pretendessem praticar atos potencialmente lesivos à concorrência consultarem previamente a Secretaria Nacional de Direito Econômico ("SNDE") acerca da validade dos referidos atos.

2. A Lei no 8.884/1994 revogou a Lei no 8.158/1991 e alterou o sistema de consultas prévias, transferindo ao Cade a competência para responder "sobre a legalidade de atos ou ajustes que de qualquer forma possam caracterizar infração da ordem econômica".

3. A redação inicialmente prevista pela Lei $\mathrm{n}^{-0} 8.884 / 1994$ foi alterada pela Medida Provisória no 542/1994, que reduziu o objeto da consulta para "acordos que importem em concentração econômica", e, em seguida, completamente revogada pela Medida Provisória n⿳o 681/1994, ${ }^{2}$ iniciando-se, assim, uma discussão acerca da sobrevivência do instituto da consulta no SBDC.

4. Os julgamentos que sobrevieram sedimentaram o entendimento de que caberiam consultas prévias acerca de condutas potencialmente anticompetitivas. Tal entendimento foi regulamentado, primeiramente, pela Resolução no 10/1997 e, posteriormente, pela Resolução no 18/1998.

5. A Resolução no 18/1998 permaneceu em vigor até 2007, quando foi publicada a Resolução no 45, que manteve em sua maioria o regime então existente até a entrada em vigor da Lei no $12.529 / 2011$.

6. Apesar de constituir um importante instrumento de orientação e de comunicação entre os administrados e a autoridade antitruste acerca de eventuais atos e/ou comportamentos lesivos à concorrência, podendo inclusive viabilizar um controle preventivo de condutas anticompetitivas, o que se observa ao longo de sua existência é que o instituto da consulta é extremamente subaproveitado. Desde sua criação, menos de 90 consultas foram apresentadas e apreciadas por este Conselho, o que perfaz uma média de 6 consultas por ano.

\section{II.2 O instituto da consulta no âmbito da legislação vigente}

7. A Lei no $12.529 / 2011$ reafirmou o instituto da consulta previsto na legislação anterior, prevendo que o Tribunal do Cade pode responder a consultas "sobre condutas em andamento", sendo que normas complementares regulamentarão o procedimento.

2 A Medida Provisória no 681/1994 foi convertida na Lei no 9.069/1995. 
Artigo 9요 $\S 4$ ㅇ. O Tribunal poderá responder consultas sobre condutas em andamento, mediante pagamento de taxa e acompanhadas dos respectivos documentos.

$\S$ 5․ O Cade definirá, em resolução, normas complementares sobre o procedimento de consultas previsto no $\S 4^{\circ}$ deste artigo.

Artigo 23. Ficam instituídas as taxas processuais sobre os processos de competência do Cade, no valor de $\mathrm{R} \$ 45.000,00$ (quarenta e cinco mil reais), que têm como fato gerador a apresentação dos atos previstos no artigo 88 desta Lei, e no valor de $\mathrm{R} \$ 15.000,00$ (quinze mil reais) para processos que têm como fato gerador a apresentação de consultas de que trata o $\S 4^{\circ}$, do artigo 9o desta Lei.

8. Muito embora não exista, até o momento, a regulamentação prevista pela Lei, reconheço inicialmente duas premissas: (i) a inexistência de regulamentação não pode inviabilizar o exercício do instituto; e (ii) é possível, com base nos dispositivos da Lei no $12.529 / 2011$ e no restante da legislação aplicável, extrair conclusões acerca dos pressupostos mínimos para conhecimento de uma consulta em casos referentes a Atos de Concentração - como a ora em análise.

9. Nesse sentido, divido os requisitos mínimos para apresentação da consulta em Atos de Concentração em três aspectos: (i) legitimidade; (ii) objeto; e (iii) dispositivo.

10. Primeiramente, no que tange à legitimidade para propor uma consulta perante o Cade, o consulente deve demonstrar seu efetivo interesse na causa, revelando que a pretensão por ele deduzida guarda relação de pertinência direta com seu objeto de atuação.

11. A comprovação do real interesse tem inspiração no artigo 9o, da Lei no 9.784/1999, o qual dispõe que são legitimados para atuar em um processo administrativo os titulares ou representantes de direitos ou interesses que possam ser afetados pelo objeto do processo.

12. Da mesma forma, a necessidade de haver pertinência temática entre o objeto da consulta e o segmento de atuação do consulente faz-se à semelhança do que ocorre nos processos relativos ao controle concentrado de constitucionalidade. A jurisprudência do Supremo Tribunal Federal ("STF") é pacífica no sentido de que são legitimados especiais para a propositura de uma ação direta de constitucionalidade ("ADI"), nos termos da Lei no 9.868/1999, aqueles que guardem relação de causalidade entre a norma questionada na ADI e os 
interesses juridicamente defendidos. Nesse sentido, reproduzem-se algumas, dentre tantas, decisões do STF:

EMENTA: Ação Direta de Inconstitucionalidade. Confederação dos Servidores Públicos do Brasil (CSPB). Ausência de legitimidade ativa "ad causam" por falta de pertinência temática - insuficiência, para tal efeito, da mera existência de interesse de caráter econômico-financeiro. Hipótese de incognoscibilidade. Ação direta não conhecida. $\mathbf{O}$ requisito da pertinência temática - que se traduz na relação de congruência que necessariamente deve existir entre os objetivos estatutários ou as finalidades institucionais da entidade autora e o conteúdo material da norma questionada em sede de controle abstrato - foi erigido à condição de pressuposto qualificador da própria legitimidade ativa "ad causam" para efeito de instauração do processo objetivo de fiscalização concentrada de constitucionalidade. Precedentes. ${ }^{3}$ [grifo nosso]

$* * * * * * * * * * * * * * * * * * * * * * * * * * * * * * * * * * * * * * * * * * * * * * * * * * * * * * * * * * * * * * * * * * * * * * * * * *$

EMENTA: Agravo regimental em ação direta de inconstitucionalidade. Confederação dos Servidores Públicos do Brasil e Estatuto Nacional da Microempresa e da Empresa de Pequeno Porte. Ausência de pertinência temática. 1. Não há pertinência temática entre o objeto social da Confederação Nacional dos Servidores Públicos do Brasil, que se volta à defesa dos interesses dos servidores públicos civis, e os dispositivos impugnados, que versam sobre o regime de arrecadação denominado de "Simples Nacional". 2. Agravo regimental a que se nega provimento. ${ }^{4}$ [grifo nosso]

13. Também vale transcrever decisão proferida por este Conselho na Consulta no 59, na qual se entendeu pelo não conhecimento da consulta apresentada em virtude da falta de legitimidade do consulente:

Para fins de caracterização do legítimo interesse, dispõe a Resolução no 18 que as consultas que versarem sobre condutas em andamento devem ser propostas pelo autor da prática do ato e que as consultas

Ação Direta de Constitucionalidade no 1.157 . Relator: Ministro Celso de Mello. Julgado em: $1^{\mathrm{o}}$ de dezembro de 1994.

4 Ação Direta de Inconstitucionalidade no 3.906. Relator: Ministro Menezes Direito. Julgamento: 7 de agosto de 2008 . 


\section{que versarem sobre ato ou contrato em tese devem ser propostas por quem possa ser considerado potencial participante direto da transa- ção hipotética submetida à análise. ${ }^{5}$}

14. No que concerne ao objeto de uma consulta, o artigo 9 , $\S^{4^{\circ}}{ }^{\circ}$, da Lei no 12.529/2011 é patente no sentido de que as consultas devem necessariamente tratar de "condutas em andamento". Aqui, vale lembrar que o conceito "condutas" se refere a comportamentos potencialmente anticompetitivos e a operações configuradas como Atos de Concentração, sendo que, neste último caso, a consulta deve tratar de caso concreto sob análise pelo Conselho, não cabendo indagações abstratas ou hipóteses de atos e operações.

15. Não é possível, por exemplo, consultar o Cade para saber se o contrato tal ou qual deve ser notificado. Deve-se indicar espeficamente o contrato, com todas as suas cláusulas e a resposta do Conselho jamais será sobre o nome contratual atribuído, mas sim sobre o conteúdo do acordo volitivo apontado. 16. Além disso, verifica-se que, à luz do artigo 22, da Lei no 9.784/1999, também não podem ser objeto de uma consulta atos e fatos que demandem, por força de lei, procedimento próprio, como a própria apreciação do mérito de operações configuradas como Atos de Concentração nos termos do artigo 90, da Lei no 12.529/2011. Ou seja, a consulta pode destinar-se a responder se a operação deve ou não ser notificada ao Cade, porém não se pode destinar a afirmar se a operação deve ou não ser aprovada pelo Conselho.

17. Também não cabe consulta acerca de atos que não sejam de competência do Cade no âmbito do controle de Atos de Concentração Econômica. Nesse sentido, como bem exemplificado pela PFE/Cade no Memorando no 08700.003084/2013-81, "não caberia ao Cade conhecer de condutas cujo objeto fosse promover a concorrência em órgãos de governo", pois a promoção da concorrência é expressamente atribuída pela Lei no 12.529/2011 à Secretaria de Acompanhamento Econômico do Ministério da Fazenda ("Seae").

18. Ademais, outro pressuposto para o conhecimento de uma consulta é a apresentação, no momento de sua propositura, da documentação necessária à instrução do pedido. ${ }^{6}$ Como estabelecido na parte final do artigo $9^{\circ}, \S^{\circ}{ }^{\circ}$, da

5 Consulta no 59/2000. consulente: Cambucci S.A. Relator: Conselheiro Celso F. Campilongo. Julgado em: 25 de outubro de 2000.

6 Dentre a documentação necessária, está o comprovante do pagamento da taxa processual no valor de R \$15.000,00 (quinze mil reais), que, como já consolidado por este Conselho (Atos de Concentração no 08012.003063/2008-56 e no 08012.005726/2008-77), se refere à contraprestação pelo funcionamento e movimentação da máquina estatal. 
Lei no 12.529/2011, "acompanhadas dos seus documentos" requer integralidade de informações, estas suficientes a permitir uma resposta sem qualquer pesquisa adicional, sendo que pareceres econômicos ou jurídicos eventualmente acostados terão conteúdo meramente informativo. Tal qual ocorre na procedibilidade de um Mandado de Segurança, não se admite dilação probatória ao longo da tramitação do processo, pois a pretensão defendida pelo consulente deve ser comprovada de plano.

19. Por fim, em relação ao dispositivo, insta salientar que, no presente caso, o papel a que se presta o instituto da consulta referente a Ato de Concentração é o de decidir acerca da necessidade de notificar as operações de cessões de direitos e obrigações referentes a contratos de concessão E\&P. Em outras palavras, à luz do disposto no artigo 52, da Lei no 9.784/1999, a resposta deste Conselho à consulta deve endereçar se devem ou não ser submetidas à apreciação da autoridade antitruste as referidas operações; eis o dispositivo.

\section{II.3 Conhecimento: análise do caso concreto}

20. Feitas as considerações acima, verifica-se que, no presente caso, estão presentes os pressupostos mínimos para o conhecimento da consulta. Vejamos:

i. Legitimidade: o IBP é uma organização privada de fins não econômicos, fundada em 1957, que conta hoje com mais de 200 empresas associadas e tem, segundo informações disponíveis em seu sítio eletrônico,? foco na "promoção do desenvolvimento do setor nacional de petróleo, gás e biocombustíveis, visando a uma indústria competitiva, sustentável, ética e socialmente responsável". Sendo assim, resta demonstrada a pertinência temática entre o segmento de atuação do IBP e o objeto em debate, revelando haver legítimo interesse para propor a consulta.

ii. Objeto: a presente consulta versa sobre a obrigatoriedade de notificação de casos concretos e em andamento relativos a cessões de direitos e obrigações que implicam a alteração da titularidade de contratos de concessão de E\&P. A análise acerca da obrigatoriedade de notificação não demanda procedimento específico nem fere a competência deste Conselho. Além disso, em que pese o voto do Conselheiro-Relator, os

7 Disponível em: <www.ibp.org.br/main.asp?Team $=\{$ A65EDC2D-02E0-4535-AF55-4E9FCC6E C4C7\}>. 
recentes julgados ${ }^{8}$ não exauriram a matéria objeto desta consulta, pois não explicitaram os motivos que levam a concluir que a cessão de direitos e obrigações em questão deve ser notificada. Por fim, observa-se que o consulente juntou aos autos toda a documentação necessária à instrução do feito, inclusive o comprovante de pagamento da taxa processual. Sendo assim, considero pertinente o objeto da presente consulta.

21. Dessa forma, considerando que foram preenchidos os pressupostos de admissibilidade, conheço da presente Consulta.

\section{Mérito}

22. A presente consulta tem por objeto esclarecer se há ou não obrigatoriedade de notificar a este Conselho operações consistentes na cessão de direitos e obrigações referentes a contratos de concessão E\&P. Importa destacar que tal consulta tem como pano de fundo orientações emitidas, em 2013, pela Agência Nacional do Petróleo, Gás Natural e Biocombustíveis ("ANP"), no sentido de que tais operações seriam de notificação e aprovação prévia deste Conselho (Ofício Circular no 003/2013/SEP e Nota Técnica ANP/CDC noo029/2013).

23. Nos termos das referidas orientações, quatro atos estariam enquadrados no conceito genérico de "cessão de direitos e obrigações" de contratos de concessão de E\&P:

i. Transferência total ou parcial de titularidade ou dos direitos e obrigações decorrentes do contrato de concessão de E\&P;

ii. Fusão, cisão ou incorporação de sociedade empresária integrante do contrato de concessão de E\&P;

iii. Mudança do operador ou do garantidor que consta do contrato de concessão de E\&P; e

8 Nesse sentido, ver:

(i) Ato de Concentração no 08700.005775/2013-19. Requerentes: Petróleo Brasileiro S.A. (Petrobras) e OGX Petróleo e Gás S.A. Relatora: Conselheira Ana Frazão. Julgado em: 22 de agosto de 2013.

(ii) Ato de Concentração 08700.008289/2013-52. Requerentes: Aurizônia Petróleo S.A. e UTC Óleo e Gás S.A. Relatora: Conselheira Ana Frazão. Julgado em: 5 de fevereiro de 2014.

(iii) Ato de Concentração no 08700.008292/2013-76. Requerentes: UTC Óleo e Gás S.A. e Potióleo S.A. Relator: Conselheiro Alessandro Octaviani Luis. Julgado em: 5 de fevereiro de 2014. 
iv. Alteração de composição societária, direta ou indireta, que implique a transferência do controle majoritário do concessionário.

24. Nos termos do próprio Ofício Circular no 003, à exceção do item (iii), todas as hipóteses de cessão de direitos e obrigações de contratos de concessão de E\&P são de notificação obrigatória ao CADE. In verbis:

Do ponto de vista das definições contidas nos contratos de concessão, apenas o item [mudança de operador ou garantidor] poderia, em tese, constituir hipótese de ato considerado cessão de direito, mas não ato de concentração para fins da legislação antitruste. Isto porque a mera mudança de Operador ou Garantidor dentro de um mesmo consórcio, e sem que ocorra alteração societária, não ensejaria a ocorrência de qualquer hipótese prevista na Lei de Defesa da Concorrência.

25. No entanto, a controvérsia quanto à obrigatoriedade ou não de notificar diz respeito apenas à hipótese descrita do item (i), qual seja, a cessão de direitos e obrigações realizada por contrato que gera mudança de titularidade do contrato de concessão de E\&P.

26. Conforme frisado pelo IBP, haveria uma diferença entre as operações classificadas como cessão de direitos e obrigações de contrato de concessão de E\&P, sendo um equívoco equipará-las. Enquanto o contrato que transfere a titularidade de determinado contrato de concessão de E\&P geraria, no entendimento do IBP, efeitos concorrenciais nulos, o contrato que instrumentaliza a fusão, cisão ou incorporação de sociedade empresária titular do contrato de concessão de E\&P (individualmente ou em consórcio) geraria, além da mudança na titularidade, outros efeitos, atos e negócios jurídicos. O mesmo argumento é empregado quando da análise da obrigatoriedade de notificar alterações de composição societária, direta ou indireta, que impliquem a transferência do controle majoritário do concessionário:

[É espécie de cessão de direitos e obrigações de contrato de concessão de E\&P] o contrato de compra e venda de ações/quotas, ou qualquer outro contrato que altera a composição societária, direta ou indireta e que implique a transferência do controle (entendido como a titularidade de cinquenta por cento mais uma das ações ou quotas do total com direito de voto) de empresa titular do contrato de concessão de E\&P (individualmente ou em consórcio); contrato este que envolve 
participação societária e que obviamente também gera outros efeitos, atos e negócios jurídicos, além da mera mudança (direta ou indireta) na titularidade de um contrato de concessão. ${ }^{9}$ [grifos nossos]

27. De acordo com o IBP, o entendimento da ANP de que a cessão de direitos e obrigações que altera a titularidade de contrato de concessão de E\&P deve ser notificada ao CADE, " não resiste a uma interpretação sistemática e cuidadosa da Lei no 12.529/2011, além de não estar alinhada com a prática internacional da indústria do petróleo, o que causa impacto negativo ao segmento de EEP que se desenvolve no Brasil".

\section{III.1 Cessão de direitos e obrigações em contratos de concessão de E\&P}

\section{III.1.1 Considerações iniciais}

28. Antes de entrar na obrigatoriedade ou não de notificação ao Cade, convém fazer uma breve explanação sobre as formas de cessão de direitos e obrigações que alteram a titularidade de contratos de concessão de E\&P.

29. A cessão de direitos e obrigações que gera mudança na titularidade de contrato de concessão de E\&P pode-se dar em diferentes situações ou, mais especificamente, instrumentalizar diferentes condutas típicas da indústria do petróleo no segmento de E\&P. O consulente traz uma clara explicação dessas condutas, distinguindo entre três categorias: (i) "Farm-out Agreements - FoA"; (ii) "withdrawal" (exercício do direito de retirada); e (iii) "default".

30. O FoA, conforme nota o IBP, estabelece os direitos e obrigações acordados entre cedente e cessionário, em âmbito privado, para fins da cessão, total ou parcial, de participação em contrato de concessão de E\&P. A empresa que atua como concessionária (individualmente ou em consórcio) é denominada farmor e a empresa que deseja adquirir a parcela ou a totalidade destes direitos e obrigações é denominada farmee.

9 Ao fazer referência a "contrato de compra e venda de ações/quotas, ou qualquer outro contrato que altera a composição societária e que implique a transferência do controle (...) de empresa titular do Contrato de Concessão de EEP", resta claro que o IBP considera como Concessionário, em casos de consórcio, as empresas que participam do consórcio vencedor e não o consórcio em si. 
31. A cessão de direitos e obrigações no caso de withdrawal pressupõe que um consórcio figure como concessionário do contrato de concessão de E\&P. Ao formar tal consórcio, as partes consorciadas celebram um contrato privado denominado Joint Operating Agreement - JOA, que regulamenta os direitos e obrigações dos consorciados, bem como a forma como estes darão cumprimento ao contrato de concessão de E\&P. O JOA prevê, dentre outras coisas, o direito de retirada de uma das partes consorciadas do contrato de concessão de E\&P, no qual não mais deseja permanecer como concessionário. A instrumentalização desta retirada se dá, por seu turno, por meio de uma cessão de direitos e obrigações.

32. A hipótese de cessão de direitos e obrigações por default também pressupõe a celebração de um $J O A$. O default, porém, diz respeito à cláusula a qual determina que as consorciadas que se tornam inadimplentes, deixando de cumprir as suas obrigações nos prazos devidos, se obrigam a ceder a sua posição no contrato de concessão de E\&P e no respectivo consórcio às empresas não inadimplentes. Tal cessão de posição contratual se dá por meio de uma cessão de direitos e obrigações. A cláusula de default visa, dessa forma, a viabilizar o adequado cumprimento do contrato de concessão de E\&P, mantendo a concessão indene e as obrigações do concessionário atendidas, caso alguma das empresas consorciadas venha a se tornar inadimplente.

\section{III.1.2 Enquadramento nos artigos 88 e seguintes, da Lei $n^{\circ}$ $12.529 / 2011$}

33. Os artigos 88 e 90, da Lei no 12.529/2011, estabelecem quais operações são consideradas Atos de Concentração para efeitos de notificação obrigatória ao Cade. O critério estabelecido pelo artigo 88 se restringe ao faturamento das partes envolvidas na operação, não causando maiores controvérsias.

34. O artigo 90 indica quatro hipóteses em que se realiza um Ato de Concentração para fins de notificação obrigatória ao Cade:

Art. 90. Para os efeitos do art. 88 desta Lei, realiza-se um ato de concentração quando:

I - 2 (duas) ou mais empresas anteriormente independentes se fundem; 
II - 1 (uma) ou mais empresas adquirem, direta ou indiretamente, por compra ou permuta de ações, quotas, títulos ou valores mobiliários conversíveis em ações, ou ativos, tangíveis ou intangíveis, por via contratual ou por qualquer outro meio ou forma, o controle ou partes de uma ou outras empresas;

III - 1 (uma) ou mais empresas incorporam outra ou outras empresas; ou

IV - 2 (duas) ou mais empresas celebram contrato associativo, consórcio ou joint venture.

Parágrafo único. Não serão considerados atos de concentração, para os efeitos do disposto no art. 88 desta Lei, os descritos no inciso IV do caput, quando destinados às licitações promovidas pela administração pública direta e indireta e aos contratos delas decorrentes.

35. Conforme se pode constatar da leitura do dispositivo, para determinar a obrigatoriedade de notificação, não basta verificar que a operação sob análise se enquadra em uma das hipóteses de realização de Ato de Concentração elencadas nos incisos I ao IV. Há que se averiguar também se a operação não se qualifica como exceção à obrigação de notificar, uma vez que subsumível ao parágrafo único do artigo em questão.

36. Não se tratando de fusão ou incorporação (incisos I e III), como se depreende da leitura dos elementos da consulta, a questão que se coloca, portanto, é se as cessões de direitos e obrigações que alteram a titularidade de contrato de concessão de E\&P se enquadrariam no inciso II, que trata da aquisição do controle ou de parte de empresa, ou no inciso IV, que diz respeito à celebração, por duas ou mais empresas, de contrato associativo, consórcio ou joint venture.

\section{III.7.2.1 Inciso II do artigo 90}

37. Decisões proferidas pelo Cade, no que tange às cessões de direitos e obrigações que alteram a titularidade de contrato de concessão, indicam que as operações em comento se enquadram no inciso II do artigo 90. 
38. No Ato de Concentração no $08700.005775 / 2013-19,{ }^{10}$ por exemplo, a Superintendência-Geral sustentou que a operação de aquisição, por parte da OGX, de participação de $40 \%$ detida pela Petrobras em contrato de concessão de E\&P corresponde à previsão do inciso II, artigo 90, da Lei no 12.529/2011.

Esta Superintendência entende que a operação apresentada deve ser conhecida, em consonância com o Parecer no 182/2013 - PFE Cade/ PGF/AGU. Convém ressaltar que o presente caso guarda similaridade com recentes julgados deste Conselho, que abordaram operações envolvendo blocos para extração de petróleo. Ademais, a operação em análise enquadra-se no disposto no inciso II, artigo 90, da Lei no $12.529 / 2011$, na medida em que a OGX adquire uma participação de $40 \%$ em um ativo específico. ${ }^{11}$ [grifo nosso]

39. Ademais, nos Atos de Concentração no 08700.008292/2013-76 ${ }^{12}$ e no $08700.008289 / 2013-52,{ }^{13}$ faz-se referência a esse mesmo parecer da Superintendência-Geral, justificando explicitamente o enquadramento da operação sob análise no artigo 90, inciso II, da Lei no 12.529/2011.

40. Há de se ressaltar, todavia, para além da alusão ao artigo 90, inciso II, que foi feita no parecer da Superintendência, que não foram explicitados os motivos que levam a concluir que a cessão de direitos e obrigações poderia ser entendida como aquisição de ativos no sentido colocado pelo artigo 90, II (que leva à aquisição do controle ou parte de uma empresa).

41. O IBP apresenta argumentos de diferentes ordens para justificar o não enquadramento das cessões de direitos e obrigações ora analisadas no artigo 90, II, da Lei no 12.529/2011:

As cessões de direitos e obrigações que envolvem apenas a alteração da titularidade nos contratos de concessão de E\&P não se subsumem ao inciso II do artigo 90 da Lei no 12.529/2011, pois (i) não implicam em

\footnotetext{
10 Ato de Concentração no 08700.005775/2013-19. Requerentes: Petróleo Brasileiro S.A. (Petrobras) e OGX Petróleo e Gás S.A. Relatora: Conselheira Ana Frazão. Julgado em: 22 de agosto de 2013.

11 Parecer Técnico da Superintendência-Geral no 205, p. 2.

12 Ato de Concentração no 08700.008292/2013-76. Requerentes: UTC Óleo e Gás S.A. e Potióleo S.A. Relator: Conselheiro Alessandro Octaviani Luis. Julgado em: 5 de fevereiro de 2014.

13 Ato de Concentração 08700.008289/2013-52. Requerentes: Aurizônia Petróleo S.A. e UTC Óleo e Gás S.A. Relatora: Conselheira Ana Frazão. Julgado em: 5 de fevereiro de 2014.
} 
aquisição de participações societárias; (ii) não representam a aquisição de ativos concorrencialmente relevantes, pois não implicam a transferência de participação de mercado; e (iii) não compreendem a aquisição do controle ou de partes da empresa.

42. A simples leitura do dispositivo em questão revela que tanto o argumento apresentado no item (i) quanto o apresentado no item (ii) não correspondem com o que determina a Lei oㅗ 12.529/2011. Isso porque se baseiam em critérios para caracterizar Atos de Concentração que não são os estabelecidos pela Lei. 43. O artigo 90, II, não fala em aquisição de participação societária, mas sim em aquisição de controle ou parte de empresa. No mesmo sentido, a Lei não especifica que as aquisições devem ser de ativos concorrencialmente relevantes (ou que não sejam neutros). A relevância dos ativos adquiridos em termos concorrenciais não compreende elemento para fins de conhecimento do Ato de Concentração. Relevância é elemento para deliberação de Ato de Concentração.

44. À semelhança do quanto observado pelo i. Conselheiro Alessandro Octaviani Luis no julgamento dos Atos de Concentração nos 08012.001875/ 2010-81, 08012.001879/2010-60, 08012.002018/2010-07 e 08012.002259/2012-18, mesmo contratos aleatórios, a despeito de não implicarem certeza acerca dos resultados advindos da celebração do contrato, podem sim acarretar efeitos na estrutura competitiva do setor, desafiando a análise da autoridade antitruste. $^{14}$

45. A reconfiguração do consórcio, com a permanência de um ou mais players, continua a exercer atividade econômica organizada para a produção e circulação de bens e/ou de serviços.

A grande dificuldade em compreender o conceito de empresa para aqueles que iniciam o estudo do direito empresarial está no fato de que

14 Nos Atos de Concentração n오 $08012.001875 / 2010-81,08012.001879 / 2010-60,08012.002018 / 2010-$ 07 e 08012.002259/2012-18, a análise tratava dos direitos minerários referentes à exploração do calcário, principal insumo para a produção do cimento. Contudo, os entendimentos aventados no julgamento dos referidos Atos de Concentração podem ser aqui aplicados, até mesmo pela semelhança de tratamento, dado pela Constituição Federal, acerca da exploração de minérios e da exploração de petróleo. Nos termos dos artigos 176 e 177 da Constituição Federal, a pesquisa e a lavra das jazidas de minérios e de petróleo constituem monopólio da União, sendo garantidos aos concessionários os produtos, porventura existentes, derivados de sua exploração. 
a expressão é comumente utilizada, coloquialmente, de forma atécnica. Empresa é, na verdade, um conceito abstrato, que corresponde, como visto, a uma atividade econômica organizada, destinada à produção ou à circulação de bens ou de serviços. Não se deve confundir, pois, empresa com sociedade empresária. ${ }^{15}$

Se empresário é o exercente profissional de uma atividade econômica organizada, então empresa é uma atividade; a de produção ou circulação de bens e serviços. É importante destacar a questão. Na linguagem cotidiana, mesmo nos meios jurídicos, usa-se a expressão "empresa" com diferentes e impróprios significados. (...) A empresa, enquanto atividade, não se confunde com o sujeito de direito que a explora, o empresário. ${ }^{16}$

46. O fato de os consórcios constituírem-se por meio de um contrato, não possuírem personalidade jurídica e não imporem a presunção de solidariedade passiva entre os consorciados não prejudica sua eventual caracterização como empresa. Afinal, a sociedade em comum $^{17}$ e a sociedade em conta de participação $^{18}$ são exemplos de sociedades que, quando direcionam o exercício profissional de sua atividade econômica para o mercado (produção ou circulação de bens ou serviços), constituem sociedades empresárias não personificadas. Quanto à ausência de presunção de solidariedade passiva entre os consorciados, o mesmo se aplica, uma vez que há outras empresas que tampouco impõem tal solidariedade. A sociedade limitada ${ }^{19}$ e a sociedade anônima ${ }^{20}$ são sociedades, em sua maioria empresárias, ${ }^{21}$ de responsabilidade limitada. ${ }^{22}$ Por fim, o fato de o consórcio constituir-se por meio de um contrato mais o

15 RAMOS, André Luiz Santa Cruz. Curso de direito empresarial: o novo regime jurídicoempresarial brasileiro. Salvador: Podivm, 2008. p. 56.

16 COELHO, Fábio Ulhoa. Manual de direito comercial. 13. ed. São Paulo: Saraiva, 2002. p. 12.

17 Artigos 986 a 990 do Código Civil.

18 Artigos 991 a 996 do Código Civil.

9 Artigos 1.052 a 1.087 do Código Civil.

20 Artigos 1.088 a 1.089 do Código Civil e Lei das Sociedades Anônimas.

${ }^{21}$ Conforme estabelece o artigo 983 do Código Civil, as sociedades simples podem se constituir pelos tipos "sociedade limitada" e "sociedade anônima":

Art. 983. A sociedade empresária deve constituir-se segundo um dos tipos regulados nos arts. 1.039 a 1.092; a sociedade simples pode constituir-se de conformidade com um desses tipos, e, não o fazendo, subordina-se às normas que lhe são próprias.

22 Na sociedade limitada, a responsabilidade de cada sócio é restrita ao valor de suas quotas (art. 1.052 do Código Civil). Na sociedade anônima, a responsabilidade dos sócios ou acionistas será limitada ao preço de emissão das ações subscritas ou adquiridas (Lei das Sociedades Anônimas). 
aproxima do que afasta de outros tipos empresariais, haja vista que todas as sociedades são constituídas pela celebração de um contrato, cuja formalização variará de acordo com o tipo societário.

47. Dessa forma, as definições legal e doutrinária de empresa e de consórcio, aliadas às características específicas do consórcio considerado no presente caso, não deixam dúvidas quanto ao fato de o consórcio concessionário de contrato de concessão de E\&P ser empresa. Isso, somado aos argumentos anteriormente apresentados, evidencia que cessão de direitos e obrigações de contrato de concessão de E\&P realizada por um consórcio, da mesma forma que a cessão realizada por uma única empresa, enquadra-se na hipótese do artigo 90, inciso II, da Lei no $12.529 / 2011$.

\section{III.1.2.2 Inciso IV do artigo 90}

48. O artigo 90, inciso IV, da Lei no 12.529/2011, trata dos Atos de Concentração realizados por meio da celebração, por duas ou mais empresas, de contratos associativos, consórcios e joint ventures.

49. O IBP argumenta que a cessão de direitos e obrigações que altera a titularidade de contrato de concessão de E\&P, quando mantém ou gera a pluralidade de agentes titulares do contrato em questão, configura contrato associativo:

Na conduta de reorganização de consórcios que venceram as licitações (outro tipo de Farm-out Agreement), via "cessão de direitos e obrigações" que implica apenas mudança na titularidade dos Contratos de Concessão de E\&P, pode-se dizer que há contrato associativo ou formação de novo consórcio, que são hipóteses do inciso IV, do artigo 90, da Lei no ${ }^{-12.529 / 2011 . ~}$

50. No mesmo sentido é o parecer de Celso F. Campilongo, bem como o parecer de Alexandre Santos do Aragão, segundo o qual "[consórcios] seriam sempre, qualquer que seja sua conceituação doutrinária, contratos associativos, celebrados com vistas à cooperação das partes (...)".

51. Nos Atos de Concentração nos 08012.002870/2012-38, 08012.006706/ 2012-08, 08700.003898/2012-34 e 08700.003937/2012-01, a i. Conselheira Ana Frazão explicitou os elementos que devem ser considerados para determinar se certo contrato se enquadra como contrato associativo. Partindo das 
definições de consórcio e de joint venture, as quais apontam como espécies de contratos associativos, a Conselheira explica:

\begin{abstract}
[A] mera referência à cooperação ou colaboração não é suficiente para definir os contratos associativos, considerando que são aspectos comuns a todos os contratos (...).
\end{abstract}

[No entanto], enquanto nos contratos comutativos a cooperação é um dever lateral, já que as prestações das partes são naturalmente distintas e contrapostas, nos contratos associativos a cooperação corresponde à própria prestação ou aos deveres principais assumidos pelas partes.

Isso acontece porque os contratos comutativos ou de troca partem da premissa de que as necessidades das partes são diferentes. Já nos contratos associativos ou plurilaterais, as necessidades das partes são as mesmas ou muito próximas, motivo pelo qual são reunidas em torno do fim comum que, por sua vez, impõe o paralelismo do comportamento das partes. (...)

Não é sem razão que Luís de Lima Pinheiro define o contrato associativo em sentido convergente à definição de contrato plurilateral de Ascarelli, considerando-o um contrato de cooperação que envolve igualmente uma organização de pessoas. No mesmo sentido, encontra-se Luís Domingos Silva Morais, segundo o qual os contratos associativos são caracterizados por uma solidariedade de interesses, em que as vantagens de um são as vantagens do outro. ${ }^{23}$

52. Percebe-se facilmente que o consórcio e, mais especificamente, o consórcio titular de contrato de concessão de E\&P (seja ele aquele firmado para participar da licitação ou aquele resultante da cessão de direitos e obrigações de contrato concessão de E\&P), tem a cooperação como dever principal; envolvem a reunião, a organização das partes, em torno de fim comum que lhes impõe o paralelismo de comportamento; e, diferentemente dos contratos comutativos, têm a solidariedade de interesses entre as partes como característica central. Desse modo, resta claro que tanto o consórcio firmado para participar da licitação, quanto o consórcio resultante da cessão de direitos e obrigações de

23 MORAIS, Luís Domingos Silva. Empresas comuns - joint ventures - no direito comunitário da concorrência. Coimbra: Almedina. p. 178. 
contrato de E\&P, são espécies de contratos associativos e se enquadram no disposto no artigo 90, IV, da Lei no $12.529 / 2011$.

53. Haveria, pois, uma dupla incidência dos contratos sob análise no artigo 90: trata-se de ativo (inciso II) e também de contrato associativo (inciso IV).

\section{III.1.2.3 Parágrafo único do artigo 90}

54. O IBP, todavia, sustenta que as cessões de direitos e obrigações que alteram a titularidade de contrato de concessão de E\&P se enquadrariam na exceção prevista pelo parágrafo único do artigo 90, da Lei no 12.529/2011.

55. Nesse sentido, Alexandre Santos de Aragão, em seu parecer, argumenta que "parece claro que os contratos de cessão são decorrentes da licitação" e que, portanto, estariam "contemplados no final do parágrafo único como imunes ao controle de estruturas prévio".

56. Celso F. Campilongo também sustenta que os contratos de cessão de direitos e obrigações que alteram a titularidade do contrato de concessão de E\&P seriam contratos decorrentes da licitação e, por essa razão, não seriam de notificação obrigatória ao CADE, nos termos do parágrafo único, do artigo 90, da Lei no 12.529/2011. In verbis:

Com a nova Lei, contratos decorrentes de licitações promovidas pela administração pública, nos casos de contratos associativos, consórcios e joint ventures, deixaram, por expressa disposição de lei recente, de ser objeto de controle de concentração pelo Cade. (...) A questão que se põe, então, é a seguinte: o que são contratos decorrentes de licitações promovidas pela administração pública? (...) É preciso distorcer muito - para não dizer subverter por completo - a clarividência do texto legal para não reconhecer que as cessões dos contratos licitados são a mais pura manifestação decorrente da licitação.

57. Extraio, contudo, interpretação diversa dos ilustres pareceristas. Na minha ótica:

i. Não são Atos de Concentração de notificação obrigatória ao Cade os contratos associativos, consórcios e joint ventures, quando destinados às licitações promovidas pela Administração Pública direta e indireta; e 
ii. Não são Atos de Concentração de notificação obrigatória ao Cade os contratos associativos, consórcios e joint ventures, quando destinados aos contratos decorrentes das licitações promovidas pela Administração Pública direta e indireta.

58. A argumentação do IBP e dos pareceres por ela aduzidos fiou-se justamente na premissa de que, além dos contratos associativos, consórcios e joint ventures destinados à licitação, os contratos decorrentes da licitação também seriam "sujeitos" aptos a se qualificar como Atos de Concentração não obrigatoriamente notificáveis.

59. Como bem disse a ANP, cessões de direito não são operações decorrentes da licitação pública em si, mas operações independentes, que envolvem modificação na titularidade de tais contratos após sua assinatura. Transferência direta, com alteração de elemento essencial do contrato, não pode ser entendida como contrato decorrente.

60. Assim, resulta claro que a cessão de direitos e obrigações que altera a titularidade de contrato de concessão de E\&P não é contrato destinado ao contrato de concessão E\&P, nos termos do previsto no parágrafo único do artigo 90 da Lei no 12.529/2011. Não configuram, portanto, hipótese de isenção de notificação obrigatória ao Cade, devendo a esta autoridade serem submetidos.

\section{Conclusão}

61. Assim, com base no acima exposto, voto:

i. Pelo conhecimento da presente Consulta; e

ii. Pela obrigatoriedade de notificação ao Cade das operações de cessão de direitos e obrigações que altere a titularidade dos contratos de concessão para exploração e produção de petróleo e gás natural. É o voto.

Brasília, 02 de abril de 2014.

\section{GILVANDRO V. COELHO DE ARAUJO Conselheiro do Cade}

